\title{
Extraction and purification of C-phycocyanin from Spirulina platensis (CCC540)
}

\author{
Devendra Kumar • Dolly Wattal Dhar • \\ Sunil Pabbi $\cdot$ Neeraj Kumar $\cdot$ Suresh Walia
}

Received: 25 April 2014/ Accepted: 23 June 2014/Published online: 16 July 2014

(C) The Author(s) 2014. This article is published with open access at Springerlink.com

\begin{abstract}
In this study a simple protocol was developed for purifying phycocyanin (PC) from Spirulina platensis (CCC540) by using ammonium sulphate precipitation, followed by a single step chromatography by using DEAECellulose-11 and acetate buffer. Precipitation with $65 \%$ ammonium sulphate resulted in $80 \%$ recovery of phycocyanin with purity of $1.5\left(\mathrm{~A}_{620} / \mathrm{A}_{280}\right)$. Throlugh chromatography an $80 \%$ recovery of phycocyanin with a purity of $4.5\left(\mathrm{~A}_{620} / \mathrm{A}_{280}\right)$ was achieved. In SDS_PAGE analysis, the purified PC showed the presence of two subunit $\alpha(16 \mathrm{kD})$ and $\beta(17 \mathrm{kD})$.
\end{abstract}

Keywords Spirulina $\cdot$ DEAE-Cellulose-11 Phycocyanin

\section{Introduction}

Cyanobacteria, also known as blue green algae (BGA) are a class of gram negative bacteria, which are considered to be the oldest form of life on the earth. They possess a wide

Electronic supplementary material The online version of this article (doi:10.1007/s40502-014-0094-7) contains supplementary material, which is available to authorized users.

D. Kumar $(\bowtie) \cdot$ D. W. Dhar · S. Pabbi

Centre for Conservation and Utilisation of Blue Green Algae, Indian Agricultural Research Institute, New Delhi 110012, India e-mail: devendra2228@gmail.com

\section{N. Kumar}

Microbiology Department, Kurukshetra University, Kurukshetra, India

S. Walia

Division of Agricultural Chemical, Indian Agricultural Research Institute, New Delhi, India range of coloured components, including carotenoids, chlorophyll and phycobiliproteins. Phycobiliproteins (PBPs) are large water soluble supramolecular protein aggregates involved in light harvesting in these organisms and may comprise as much as $40-60 \%$ of the total soluble protein in these cells (Bogorad 1975). These can be divided broadly into three classes based on their spectral properties: Phycoeryhrin $\left(\lambda_{\max }-565 \mathrm{~nm}\right)$, phycocyanin $\left(\lambda_{\max }-620 \mathrm{~nm}\right)$ and allophycocyanin $\left(\lambda_{\max }-650 \mathrm{~nm}\right)$ (Glazer and Bryant 1975). These are composed of two different kinds of polypeptide of which one is low molecular weight $\alpha$ unit (MW: $12-19 \mathrm{kD}$ ) and other is large $\beta$ unit (MW: $14-21 \mathrm{kD})$, and are generally present in equimolar amounts (Bernard et al. 1992).

The PBPs, mainly phycocyanin have been widely used as nutritional ingredients, natural dyes, florescent markers (Glazer and Stryer 1984), pharmaceuticals such as antioxidants (Romay and Gonzalez 2000) and anti-inflammatory reagents (Qureshi et al. 1996). Phycocyanin is used as colorant in food (chewing gums, dairy products, gellies etc.) and cosmetics such as lipstick and eye liners in Japan, Thailand and China. It has also shown to have therapeutic value (immuno-modulating activity and anticancer activity) (Lijima and Shimamatsu 1982). Phycocyanin is the most important natural blue pigment used in the food and biotechnology because of their colour, fluorescence and antioxidant properties. Cyanobacteria, as a source of PC are being exploited for a long time. But most studies have focussed on production and purification of PC from Spirulina platensis (Boussiba and Richmond 1979; Hirata et al. 2000; Minkova et al. 2003; Yan et al. 2011).

There are some difficulties in phycocyanin extraction because of multilayered cell walls and large amounts of contaminants (Stewart and Farmer 1984). Several methods have been reported for successful purification of C-PC 
(Bermejo et al. 2006; Boussiba and Richmond 1979; Chen et al. 2006; Patil et al. 2006; Santiago-Santos et al. 2004; Zhang and Chen 1999), but these methods comprised multiple steps and are time consuming, which may lead to increase in production costs and limit their widespread application.

In the present study we have described a one-step anion exchange chromatography with $\mathrm{pH}$ gradient elution for purification of C-Phycocyanin with high purity and recovery from S. Platensis (CCC540). The purity of C-PC was further demonstrated by sodium dodecyl sulfte- polyacrylamide gel electrophoresis (SDS-PAGE) and analysed by HPLC.

\section{Materials and methods}

Growth and maintenance of culture

Spirulina platensis (CCC540) was procured from the culture collection of Centre for Conservation and Utilization of Blue Green Algae (CCUBGA), IARI, New Delhi, India. Culture was maintained in chemically defined Z-Medium (Zarrouk 1966) at $28 \pm 2{ }^{\circ} \mathrm{C}$ under a light intensity of 52-55 $\mu \mathrm{mol}$ photon $\mathrm{m}^{-2} \mathrm{~s}^{-1}$ and light/dark cycles of 16:8 h.

\section{Extraction and estimation of C-Phycocyanin}

A $500 \mathrm{ml}$ of homogenized log phase (15 days old) culture was centrifuged at $4,000 \mathrm{rpm}$ to obtain pellet. The pellet was suspended in $100 \mathrm{ml}$ of $20 \mathrm{mM}$ acetate buffer containing $50 \mathrm{mM}$ sodium chloride and $0.002 \mathrm{M}$ sodium azide (pH-5.10). C-Phycocyanin was extracted by repeated freezing $\left(-20{ }^{\circ} \mathrm{C}\right)$ and thawing at room temperature until the blue color becomes in acetate buffer (Step I). Cell debris was removed by centrifugation at 5,000 rpm for $10 \mathrm{~min}$ and the extract thus obtained was termed as crude extract. Amount of C-PC was measured as described by Bennett and Bogard (1973) and purity was determined by using the formulae: Purity $=\mathrm{A}_{620} / \mathrm{A}_{280}$

\section{Purification}

The crude extract was subjected to a single step precipitation using $65 \%\left(\mathrm{NH}_{4}\right)_{2} \mathrm{SO}_{4}$ (Bio Xtra, >99\%; SigmaAldrich) and kept overnight at $4{ }^{\circ} \mathrm{C}$. The pellet was recovered by centrifugation at $27,000 \mathrm{rpm}$ for $15 \mathrm{~min}$ at $4{ }^{\circ} \mathrm{C}$ and dissolved in $10 \mathrm{ml}$ of the same extraction buffer and termed as ammonium sulfate extract (ASE). Ten ml of ASE was dialyzed against the extraction buffer using dialyses membrane (Dialyses membrane-70, MWCO; 12-14 kD) procured from Hi-Media. Dialyses was performed twice against $1,000 \mathrm{ml}$ extraction buffer, first at room temperature and again dialysed against $1,000 \mathrm{ml}$ of extraction buffer at $4{ }^{\circ} \mathrm{C}$ overnight. The resultant extract was recovered from the dialyses membrane and filtered through $0.45 \mu \mathrm{m}$ filter.

DEAE-Cellulose from Sisco Research Laboratory (SRL) was used for anion exchange chromatography. A column $(30 \times 2 \mathrm{~cm})$ was prepared for purifying the phycocyanin, and equilibrated with $150 \mathrm{ml}$ of acetate buffer ( $\mathrm{pH}-5.10)$. Dialyzed filtered sample $(10 \mathrm{ml})$ was placed on the column. A linear gradient of acetate buffer with $\mathrm{pH}$ ranging from 3.76 to 5.10 was used to developed the column and elutes were collected in $5 \mathrm{ml}$ fractions. Flow rate was kept $20 \mathrm{ml} \mathrm{h}^{-1}$. Absorption spectrum was also determined by scanning the sample in the range of 300-750 nm by using Specord 200 spectrophotometer (Analytikjena, Germany).

\section{SDS-PAGE}

A $7.5 \%$ continuous PAGE under non-denaturing conditions was carried out to reconfirm the purity of phycocyanin. The bands were visualized by Coomassie blue staining. Molecular weight of the purified phycocyanin was determined by running Novex Sharp pre stained protein marker along with the sample.

High performance liquid chromatography

Phycobiliprotein subunit separation by HPLC was performed using a reversed phase Discovery BIO Widepore $\mathrm{C}_{5}$ (Supelco, Sigma Aldrich) column $(250 \times 4.6 \mathrm{~mm}$ i.d. $)$ packed with $5 \mu \mathrm{m}$ porous silica particles (300 angstrom pore diameter). This column was operated at a flow rate of $1 \mathrm{ml} \mathrm{min}{ }^{-1}$ for optimum separation efficiency. All solutions were filtered through $0.5 \mu \mathrm{m}$ membrane filter and degassed by bubbling with helium before use. Optimization of chromatographic separations was performed using a

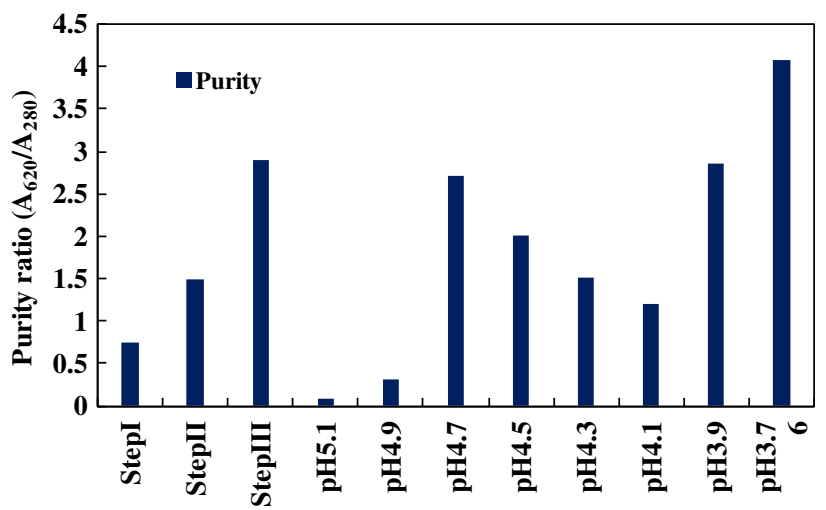

Fig. 1 Purity of phycocyanin attained at different steps with a linear gradient of $\mathrm{pH}$ from 3.76 to 5.1 
Table 1 Purity and recovery ratio of phycocyanin at each purification steps

\begin{tabular}{lcllc}
\hline Step & $\begin{array}{l}\text { Volume } \\
(\mathrm{ml})\end{array}$ & $\begin{array}{l}\mathrm{PC} \\
\left(\mu \mathrm{g} \mathrm{ml}^{-1}\right)\end{array}$ & $\begin{array}{l}\text { Purity } \\
\left(\mathrm{A}_{620} /\right. \\
\left.\mathrm{A}_{280}\right)\end{array}$ & $\begin{array}{l}\text { Recovery } \\
(\%)\end{array}$ \\
\hline Crude extract & 200 & 77.4 & 0.75 & 100 \\
$\begin{array}{c}\text { Ammonium } \\
\quad \text { sulphate pptn }\end{array}$ & 10 & 123.8 & 1.5 & 80 \\
$\begin{array}{l}\text { Dialysis } \\
\begin{array}{l}\text { DEAE column } \\
\text { chromatography }\end{array}\end{array}$ & 10 & 601.4 & 2.93 & 39 \\
\hline
\end{tabular}

Alliance system (Waters) with 2695 separation module with auto-sampler consisting of a Waters 2998 Photo Diode-Array detector (PDA) and Waters 2475 Multi $\lambda$ fluorescence detector. Excitation and emission wavelength for fluorescence detector was set at 580 and $640 \mathrm{~nm}$. The Discovery BIO Widepore $\mathrm{C}_{5}$ column was pre-equilibrated with $20 \%(\mathrm{v} / \mathrm{v})$ aqueous acetonitrile (ACN) solution containing $0.1 \%(\mathrm{v} / \mathrm{v})$ trifluoroacetic acid (TFA). Twenty $\mu \mathrm{l}$ sample $\left(200 \mu \mathrm{g} \mathrm{ml}^{-1}\right)$ was injected and elution was performed using a linear gradient from 20 to $100 \%$ (v/v) aqueous ACN (containing $0.1 \%$ TFA) in 45 min. Both PDA and fluorescence detector were connected in series for the detection of biliprotein subunits.

\section{Results and discussion}

Spirulina is used as a high quality protein mainly for phycocyanin (Eriksen 2008), which is a important cyanobacterial accessory pigment having a number of industrial applications. Although a number of reports are available for the extraction and purification of phycocyanin from cyanobacterial strains (Schoenleber et al. 1984; Swanson et al. 1991). Extraction and purification of phycocyanin, was completed in four major steps: crude extract preparation (Step I), ammonium sulfate precipitation (Step II), dialyses (Step III) and anion exchange chromatography (Step IV) (Fig. 1). After ammonium sulphate precipitation
Fig. 2 Absorbtion spectrum of purified Phycocyanin

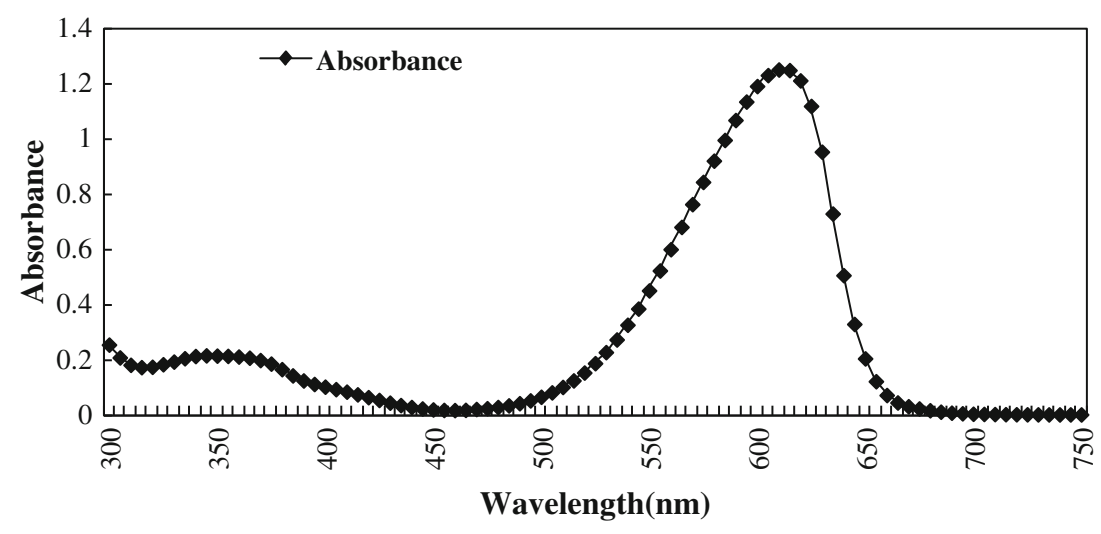

Fig. 3 Revere phase-HPLC profile of phycocyanin from Spirulina strain using PDA Detector $(620 \mathrm{~nm})$ showing $\alpha$ and $\beta$ subunit peaks

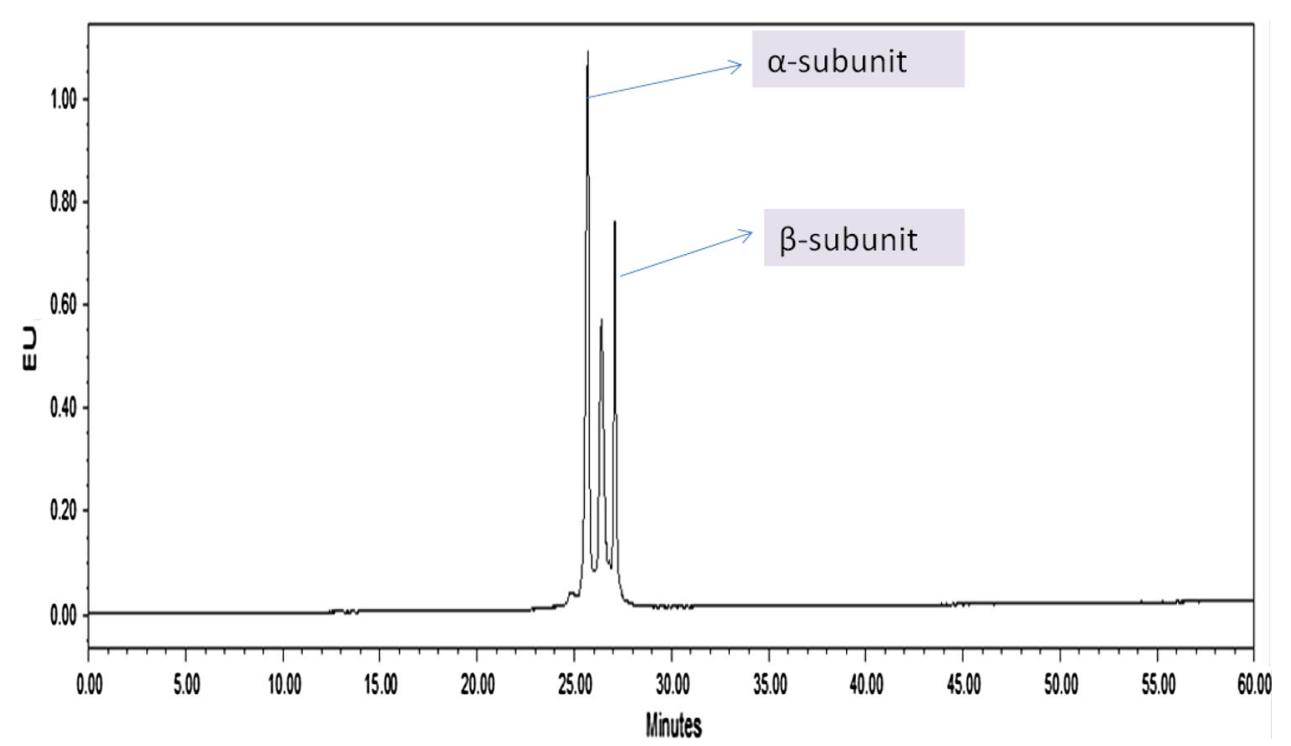



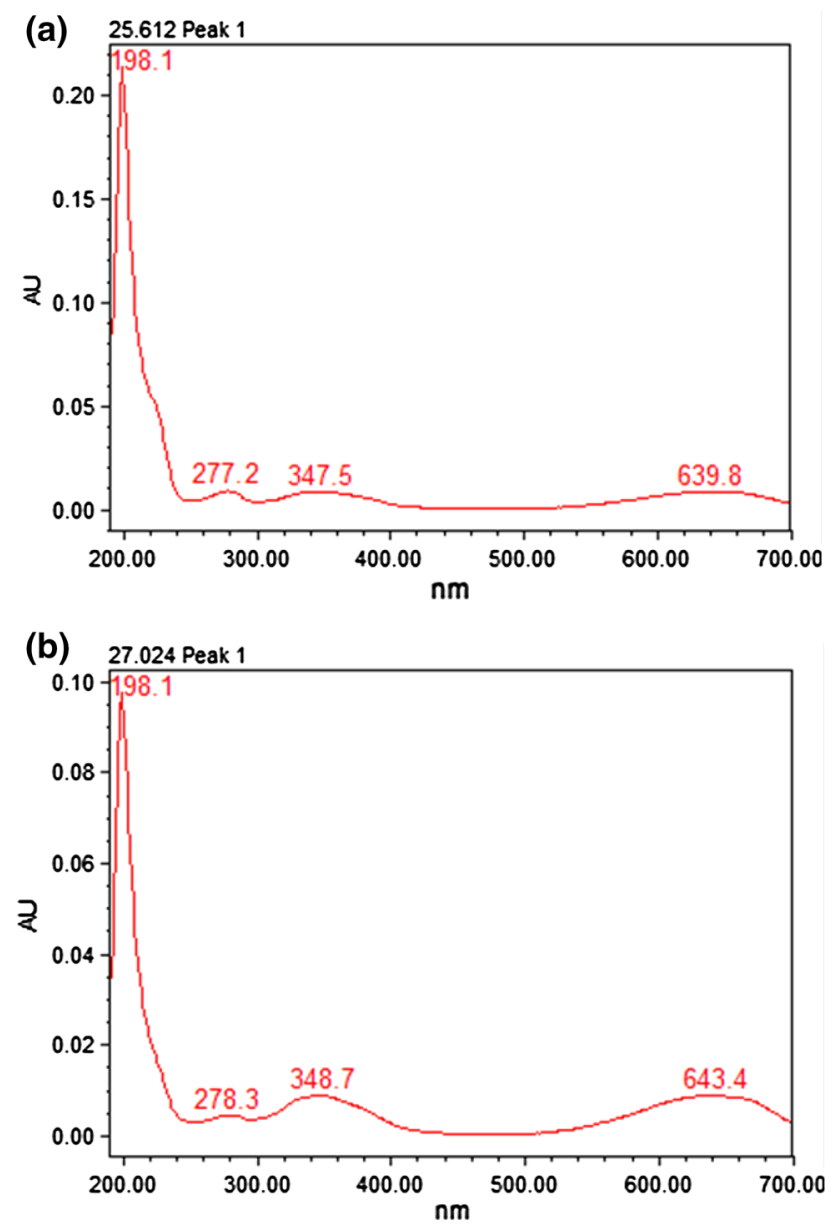

Fig. 4 a Absorbtion spectra of $\alpha$-subunit with RT 25.612. b Absorpsion spectra of $\beta$-subunit with RT 27.024

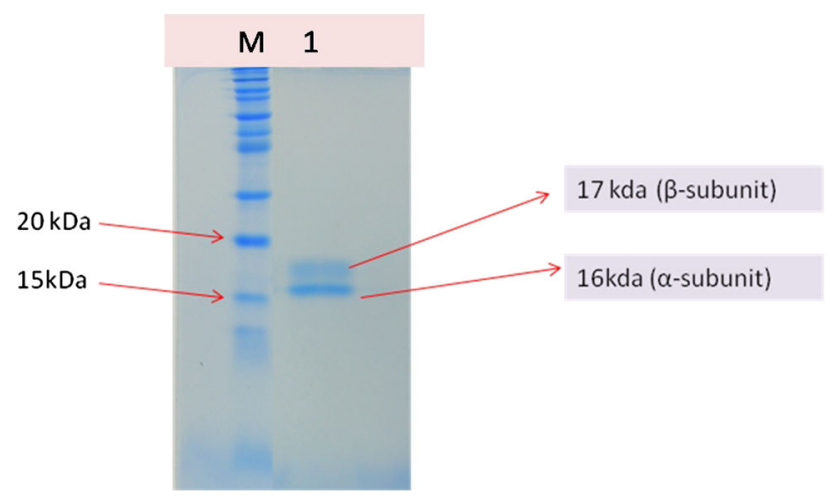

Fig. 5 SDS-PAGE of purified phycocyanin ( $M$ molecular marker, lane $1 \mathrm{PC})$

the purity of phycocyanin was 1.5 and after dialyses purity were 2.93. But the final purity $\left(\mathrm{A}_{620} / \mathrm{A}_{280}\right)$ after anion exchange chromatography was 4.58 . So from crude extract purification to anion exchange chromatography, purity increased nearly six times. During the chromatographic separation, $\mathrm{PC}$ with maximum purity was eluted as a bright blue colored solution at pH 3.76 (Table 1). The absorption spectra of the purified PC showed a prominent peak at $620 \mathrm{~nm}$ (Fig. 2). Purity was also reconfirmed by the presence of single bands of $\alpha$-subunit (16 kDa) and $\beta$-subunit (17 kDa) during native gel electrophoresis (Fig 5). In order to further characterize the PC purified from BGA, reverse phase HPLC was performed using $\mathrm{C}_{5}$ column (Fig. 3). PDA detector set at 620 and $226 \mathrm{~nm}$ revealed two major peaks at 25.612 and $27.024 \mathrm{~min}$. When absorption spectra of these two chromatogram peaks were critically analyzed, it was found that $\mathrm{A}_{620}: \mathrm{A}_{280}$ for the first peak $\mathrm{RT}=25.612$ min (Fig. 4a) was approximately 1 , which is due to the presence of one phycocyanobilin (PCB) chromophore, thus indicating that this peak corresponds to $\alpha$ subunit of PC, while the $\mathrm{A}_{620}: \mathrm{A}_{280}$ for the second peak $\mathrm{RT}=27.024$ min (Fig. 4b) was approximately 2 , which is due to the presence of two PCB chromophores and therefore this peak corresponds to $\beta$ subunit of PC.

Acknowledgments The authors are thankful to Director IARI, New Delhi for allowing the present study at the institute and to NAIP, ICAR for financial support.

Open Access This article is distributed under the terms of the Creative Commons Attribution License which permits any use, distribution, and reproduction in any medium, provided the original author(s) and the source are credited.

\section{References}

Bennett, A. (1972). Metabolic and structural investigations of Fremeyella diplosiphon phycobiliproteins. Ph.D. thesis, Harvard University, Cambridge.

Bennett, A., \& Bogorad, L. (1973). Comparative chromatic adaptation in a filamentous blue-green alga. Journal of Cell Biology, $58,419-435$.

Bernard, C., Thomas, J. C., Mazel, D., Mousseau, A., Castets, A. M., Tandeau de Marsac, N., et al. (1992). Characterization of genes encoding phycoerythrin in the red alga Rhodella violacea: evidence for a splitting of the rpeB gene by an intron. Proceedings of the National Academy of Sciences of the United States of America, 89, 9564-9568.

Bogorad, L. (1975). Phycobiliproteins and complementary chromatic adaptation. Annual Review of Plant Physiology, 26, 369-401.

Boussiba, S., \& Richmond, A. E. (1979). Isolation and characterization of phycocyanins from the blue-green alga Spirulina platensis. Archives of Microbiology, 120, 155-159.

Bryant, D. A. (1982). Phycoerythrocyanin and phycoerythrin: Properties and occurrence in cyanobacteria. Journal General Microbiology, 128, 835-844.

Eriksen, N. T. (2008). Production of phycocyanin-a pigment with applications in biology, biotechnology, foods and medicine. Applied Microbiology and Biotechnology, 80, 1-14.

Glazer, A. N. (1985). Light harvesting by phycobilisomes. Annual Review of Biophysics and Biophysical Chemistry, 14, 47-77. 
Glazer, A. N., \& Bryant, D. A. (1975). Allo-phycocyanin B $\left(\lambda_{\max }\right.$ 671, $618 \mathrm{~mm}$ ): a new cyanobacterial phycobiliprotein. Archives of Microbiology, 104, 15-22.

Glazer, A. N., \& Cohen-Bazire, G. (1971). Subunit structure of the phycobiliproteins of blue-green algae. Proceedings of the National Academy of Sciences, 68, 1398-1401.

Grossman, A., Bhaya, D., Apt, K., \& Kohoe, D. (1995). Lightharvesting complexes in oxygenic photosynthesis: diversity, control and evolution. Annual Review of Genetics, 29, 231-288.

Guan, X., Qin, S., Zhao, F., Zhang, X., \& Tang, X. (2007). Phycobilisomes linker family in cyanobacterial genomes: divergence and evolution. International Journal of Biological Sciences, 3, 434-455.

Hirata, T., Tanaka, M., Ooike, M., Tsunomura, T., \& Sakaguchi, M. (2000). Antioxidant activities of phycocyanobilin prepared from Spirulina platensis. Journal of Applied Phycology, 12, 435-439.

Laemmli, U. K. (1970). Cleavage of structural proteins during the assembly of the head of bacteriophage T4. Nature, 227, 680-685.

MacColl, R. (1998). Cyanobacterial phycobilisomes. Journal of Structural Biology, 124, 311-334.

MacColl, R., Eisele, L. E., Williams, E. C., \& Bowser, S. S. (1996). The discovery of a novel R-phycoerythrin from and Antartic Red Alga. Journal of Biological Chemistry, 271, 17157-17160.

Mieras, G. A., \& Wall, R. A. (1968). Sub-units of the algal biliprotein phycoerythrin. Biochemical Journal, 107, 127.

Minkova, K. M., Tchernov, A. A., Tchorbadjieva, M. I., Fournadjieva, S. T., Antova, R. E., \& Busheva, M. C. (2003). Purification of C-phycocyanin from Spirulina (Arthrospira) fusiformis. Journal of Biotechnology, 102, 55-59.

Oi, V. T., Glazer, A. N., \& Stryer, L. (1982). Fluorescent phycobiliprotein conjugates for analyses of cells and molecules. Journal of Cell Biology, 93, 981-986.

Ong, L. J., \& Glazer, A. N. (1991). Phycoerythrins of marine unicellular cyanobacteria. I. Bilin types and locations and energy transfer pathways in Synechococcus sp. Phycoerythrins. Journal of Biological Chemistry, 266, 9515-9527.

Parmar, A., Singh, N. K., Kaushal, A., Sonawala, S., \& Madamwar, D. (2011). Purification, characterization and comparison of phycoerythrins from three different marine cyanobacterial cultures. Bioresource Technology, 102, 1795-1802.

Qureshi, M. A., Garlich, J. D., \& Kidd, M. T. (1996). Dietary Spirulina platensis enhances humoral and cell-mediated immune functions in chickens. Immunopharmacology and Immunotoxicology, 18, 465-476.
Ranjitha, K., \& Kaushik, B. D. (2005). Purification of phycobiliproteins from Nostoc muscorum. Journal of Scientific and Industrial Research, 64, 372-375.

Reis, A., Mendes, A., Lobo-Fernandes, H., Empis, J. A., \& Novais, J. M. (1998). Production, extraction and purification of phycobiliproteins from Nostoc sp. Bioresource Technology, 66, 181-187.

Rossano, R., Ungaro, N., D’Ambrosio, A., Liuzzi, G. M., \& Riccio, P. (2003). Extracting and purifying R-phycoerythrin from Mediterranean red algae Corallina elongate Ellis and Solander. Journal of Biotechnology, 101, 289-293.

Schoenleber, R. W., Lundell, D. J., Glazer, A. N., \& Rapoport, H. (1984). Bilin attachment sites in the $\alpha$ and $\beta$ subunits in B-Phycoerythrin. Structural studies on the singly linked phycoerythrobilins. Journal of Biological Chemistry, 259, 5485-5489.

Stanier, R. Y., Kunisawa, R., Mandal, M., \& Cohen-Bazire, G. (1971). Purification and properties of unicellular blue green algae (order Chroococcales). Bacteriological Reviews, 35, 171-205.

Swanson, R. V., Ong, L. J., Wilbanks, S. M., \& Glazer, A. N. (1991). Phycoerythrins of marine unicellular cyanobacteria. II. Characterization of phycobiliproteins with unusually high phycourobilin content. Journal of Biological Chemistry, 266, 9528-9534.

Tchernov, A. A., Minkova, K. M., Houbavenska, N. B., \& Kovacheva, N. G. (1999). Purification of phycobiliproteins from Nostoc sp. by aminohexyl-sepharose chromatography. Journal of Biotechnology, 69, 69-73.

Tripathi, S. N., Kapoor, S., \& Shrivastave, A. (2007). Extraction and purification of an unusual phycoerythrin in a terrestrial desiccation tolerant cyanobacterium Lyngbya arboricola. Journal of Applied Phycology, 19, 441-447.

Wilbanks, S. M., \& Glazer, A. N. (1993). Rod structure of a phycoerythrin II containing phycobilisome. I. Organization and sequence of the gene cluster encoding the major phycobiliprotein rod components in the genome of marine Synechococcus sp. WH8020. Journal of Biological Chemistry, 268, 1226-1235.

Yan, S., Zhu, L., Su, H., Zhang, X., Chen, X., Zhou, B., \& Zhang, Y. (2011). Single-step chromatography for simultaneous purification of C-phycocyanin and allophycocyanin with high purity and recovery from Spirulina (Arthrospira) platensis. Journal of Applied Phycology, 23, 1-6.

Zarrouk, C. (1966). Contribution a I' etude d' une cyanobacterie: Influence de divers facteurs physiques et chimiques et la photosynthese de Spirulina maxima (Setchell et Gardener) Geitler Ph.D.thesis, University of paris, France. 